\title{
The influence of a 'take home' box trainer on laparoscopic performance for gynaecological surgeons
}

\author{
Kushal Chummun • John P. Burke • Ray O'Sullivan • \\ Walter Prendiville
}

Received: 24 May 2011 / Accepted: 16 November 2011 /Published online: 11 December 2011

(C) Springer-Verlag 2011

\begin{abstract}
Laparoscopic surgery requires a unique set of technical skills. There is emphasis on increasing patient safety, and therefore, a growing need to improve laparoscopic training. The aim of this study is to determine if the use of a 'take-home' box trainer would improve gynaecological surgeon performance. Thirteen obstetricians and gynaecologists (consultants and registrars) were enrolled to receive 6 months formal laparoscopic training using a 'takehome' box trainer. Laparoscopic skills were objectively assessed using a virtual reality haptic-enhanced simulator prior to commencement and at the completion of the course utilising three defined exercises (locating and coordinating, tissue manipulation and object positioning) where task duration, path length, economy of movement, hand dominance and overall score were assessed. Data is presented as mean \pm SEM and differences between groups evaluated with ANOVA. All 13 gynaecologists completed the programme. For tissue manipulation, laparoscopic training using the box trainer reduced the task duration $(214.8 \pm 16.5 \mathrm{~s}$ vs. $147.7 \pm$ $12.6 \mathrm{~s}, P=0.04)$ and increased economy of movement ( $22 \pm$ $7.1 \%$ vs. $78.9 \pm 2.3 \%, P<0.001)$ and overall score $(11.7 \pm$ $3.1 \%$ vs. $33.7 \pm 1.8 \%, P<0.001)$. For object positioning, laparoscopic training with the box trainer reduced task duration $(280.1 \pm 40.3 \mathrm{~s}$ vs. $106.6 \pm 5.1 \mathrm{~s}, P<0.001)$ and path length $(825.3 \pm 48.3 \mathrm{~cm}$ vs. $463.4 \pm 16.8 \mathrm{~cm}, P<0.001)$ and
\end{abstract}

Presented in part at: Junior Obstetrics and Gynaecology Scientific Meeting, Ireland, 2009.

K. Chummun $\cdot$ R. O’Sullivan $\cdot$ W. Prendiville $(\bowtie)$

National Clinical Skills Centre,

Coombe Women and Infants, University Hospital,

Dublin, Ireland

e-mail: fidelma.kavanagh@gmail.com

J. P. Burke

Department of Surgery, Beaumont Hospital,

Dublin, Ireland increased overall score $(4.15 \pm 1.7 \%$ vs. $15.2 \pm 2 \%, P<$ $0.001)$. The box trainer did not significantly affect laparoscopic locating and coordinating or change hand dominance. Formal training and continuous practice using the box trainer model improves surgical skills required for laparoscopic surgery. The box trainer could be a more accessible and preferred tool for those training to become laparoscopic surgeons.

Keywords Laparoscopic training · Box trainers · Virtual reality $\cdot$ Simulation

\section{Background}

An increasing number of surgical procedures are being performed via a laparoscopic approach, which requires a unique set of technical skills. Laparoscopy can be problematic for surgical training as the learning curve is steep and significant experience is required before competency is achieved [1-4]. Reasons include altered depth perception by a two-dimensional video imaging system, new cues must be learned before spatial relationships can be reliably established, long instruments diminish tactile feedback, range of motion is limited by trocars, fulcrum effect of the body wall and video eye-hand coordination must be developed to correctly position instruments in the operative field.

The different methods of laparoscopic surgical training include traditional mentorship training in the operating theatre, live animal training, human and animal cadaver training, training using a box trainer and virtual reality training (training using computer simulation) [5].

Traditional training is not without costs and risk to the patient. The operating time has been shown to increase significantly for junior surgeons compared to senior surgeons [6-9]. Cadavers provide training outside the operating 
theatre, but have cost implications, are of limited availability, and have noncompliant tissue that may be difficult to use [10]. Live animal models are useful but problem includes difference in anatomy from humans, cost, structural facilities, ethical issues and European legislation [11, 12]. Virtual reality training shortens the time to skill acquisition in different surgical procedures and offers an ethical way of assessing the competency of a surgeon in performing a procedure without a risk to the patient [5, 13-17]. However, significant cost implications are a deterrent for many institutions.

'Take home' box trainers are alternative tools used for laparoscopic training. They are economical and can be easily acquired not only by institutions but also by trainees in laparoscopic surgery. This allows the trainee to not only practise while in hospital or on a course but also at home. The aim of the current study was to evaluate the use of a 'take home' box trainer as a learning tool in laparoscopic surgical skills for gynaecological surgeons.

\section{Methods}

Thirteen gynaecologists (10 registrars and 3 consultants) were enrolled at the National Clinical Skills Centre (NCSC) for a 6month laparoscopic training course using a 'take home' box trainer. A maximum of 16 places are available for each course at the NCSC as it allows a one to one training and monitoring. Our participants were neither laparoscopic novices nor experts and would on average perform about one to two laparoscopic procedures per week at their respective place of work.

The box trainer, evolved from a need to provide a novel take home system. Initially the 'box' consisted of storage boxes and cheaply available webcams. This system has been refined into the LaProTrain ${ }^{\circledR}$ (Fig. 1) laparoscopic simulator (Endosim Ltd, Belfast, Northern Ireland). The box trainer is light, non cumbersome and portable which encourages a long-term use even after completion of the course.

At the beginning of the course, each delegate's laparoscopic skills were assessed using a virtual reality ProMIS ${ }^{\circledR}$ enhanced laparoscopic simulator (Haptica Ltd, Dublin, Ireland).

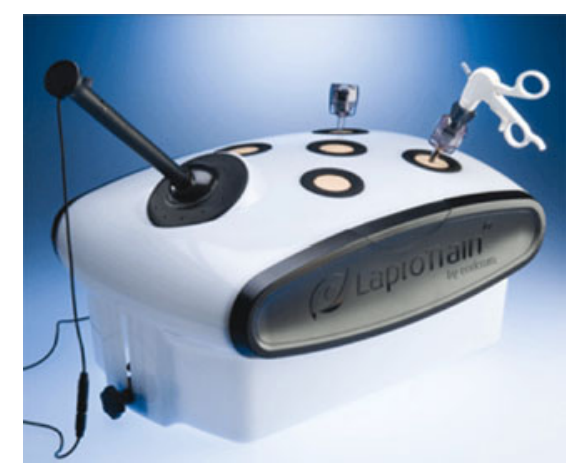

Fig. 1 The LaProTrain ${ }^{\circledR}$ box trainer
The assessment involved three precise, computer-controlled exercises (locating and coordinating, tissue manipulation and object positioning). Task duration, path length, economy of movement, change in hand dominance and the overall score were recorded.

In locating and coordinating exercise, the user must touch and/or track a series of fixed and dynamic objects in a virtual environment, while trying to avoid colliding with tissue. Audio cues and on-screen directions provide guidance. Tissue manipulation involved the user to stretch simulated tissue from one marked point to another, learning to judge tissue strength and appropriate force. Lastly, the object positioning exercise involved the user to pick up a number of objects, transfer them from one hand to another and place them in a specified target area.

The participants then attended the NCSC course once a month for 6-month period where new techniques and exercises were taught using their own individual box trainer. After each of the six training sessions, the delegates took their box trainer home where they were encouraged to practise the exercises for at least $1 \mathrm{~h}$ each day and also apply the newly learnt technique during laparoscopy. At the start of each course, prior to learning new techniques, the exercises taught previously were reviewed to identify weakness points in each participant and therefore allow targeting practice at home.

Examples of exercises (Fig. 2) on the box trainer included:

- Basic tasks such as

- touching different points on a piece of paper using graspers with the camera fixed and again with the camera tracking the grasper,

- passing beans from one grasper to another and placing beans on designated spot and

- assembling and disassembling puzzles.

- Complex drills such as

- using grasper and scissors to cut a circle marked on a surgical glove;

- performing a simulated ovarian cystectomy - this involved removing a liquid washing tablet placed inside a partially glue stuck deflated balloon without bursting the tablet;

- suturing exercises which included

extracoporal suturing, endoloop placement, intra-corporeal knot suturing.

- Specimen retrieval exercises involve using an endo-bag to retrieve different objects (e.g. liquid washing tablet) from the box trainer.

At the end of the sixth month, the participants were reassessed using the same three exercises on the ProMIS ${ }^{\circledR}$ 
Fig. 2 a Cutting exercise. b Ovarian cystectomy simulation. c-d Suturing exercises
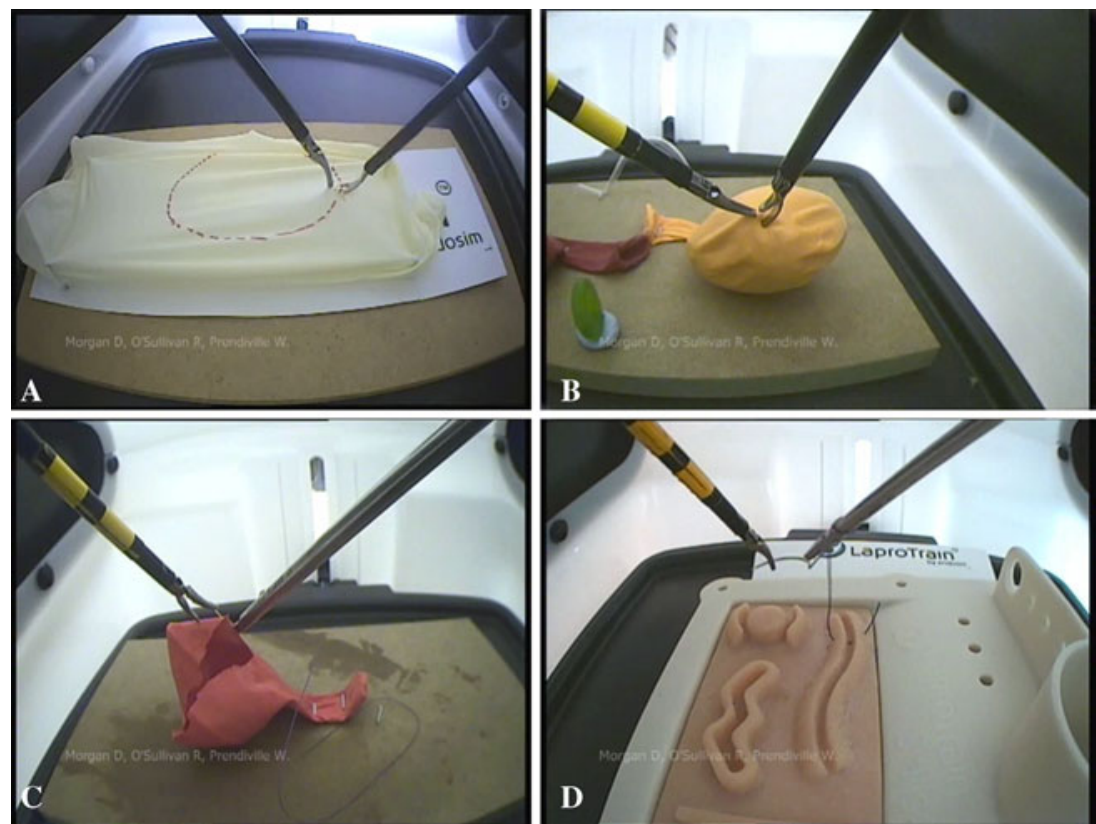

enhanced laparoscopic simulator. The task duration, path length, economy of movement, change in hand dominance and overall score were again recorded and the data compared to that at the start of the course. Data is presented as mean \pm SEM and differences between groups evaluated with ANOVA using SPSS V.12 (Chicago, IL, USA).

\section{Findings}

All 13 gynaecologists completed the programme and 100\% data was available on all participants. Results are presented under the subcategories of locating and coordinating, tissue manipulation and object positioning.
Locating and coordinating

In this subcategory, there was no significant difference between the assessment before and after training in all the measured parameters:

- task time $(410.9 \pm 29.7 \mathrm{~s}$ vs. $398.5 \pm 30.6 \mathrm{~s}, P=0.772)$ (Fig. 3a),

- path length $(925.7 \pm 86.5 \mathrm{~cm}$ vs. $963.2 \pm 71.9 \mathrm{~cm}, P=0.742)$ (Fig. 3b),

- percentage change in hand dominance $(8.4 \pm 1.6 \%$ vs. $6.8 \pm 2.1 \%, P=0.633$ ) (Fig. 3c),

- overall score $(9.9 \pm 2.3$ vs. $6.3 \pm 3.2, \quad P=0.492)$ (Fig. 3d).
Fig. 3 Change in locating and coordinating skills following box trainer use. CHP change in hand preference. No significant difference between groups, ANOVA
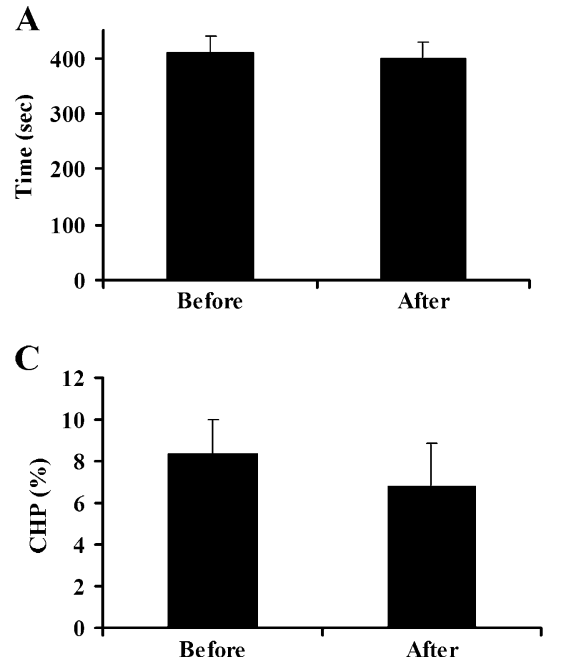

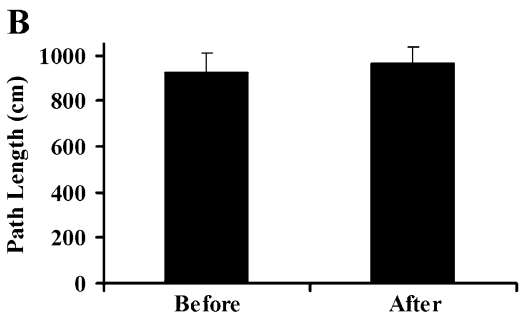

D

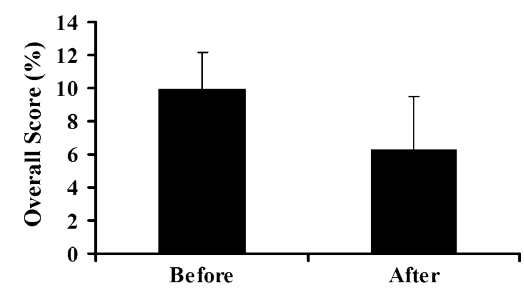


Fig. 4 Change in tissue manipulation skills following box trainer use. $C H P$ change in hand preference, $E O M$ economy of movement. $* P<0.05, \# P<0.001$, ANOVA
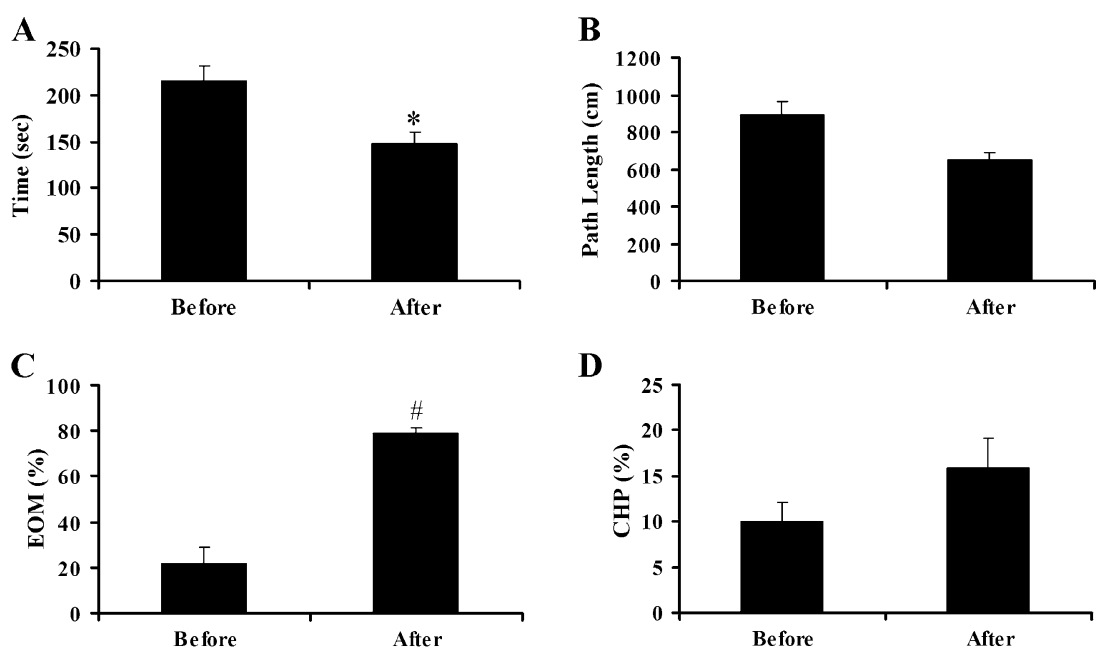

D

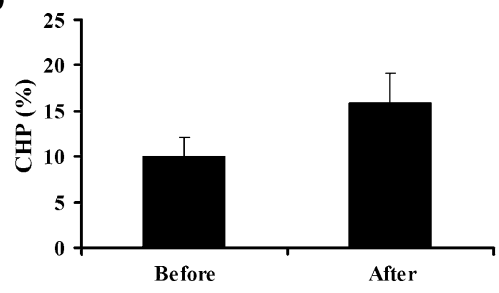

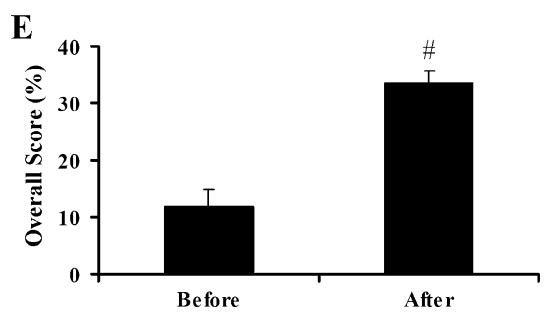

Tissue manipulation

In this subcategory, significant improvement was noted in terms of:

- $\quad$ total task time $(214.8 \pm 16.5 \mathrm{~s}$ vs. $147.7 \pm 12.6 \mathrm{~s}, P=0.04)$ (Fig. 4a),

- $\quad$ economy of movement $(22 \pm 7.1 \%$ vs. $78.9 \pm 2.3 \%, P<$ 0.001) (Fig. 4c) and

- $\quad$ overall score $(11.7 \pm 3.1 \%$ vs. $33.7 \pm 1.8 \%, P<0.001)$ (Fig. 4e).

There was however no difference between the assessment before and after training in terms of path length $(892.8 \pm$
$68.3 \mathrm{~cm}$ vs. $652.9 \pm 40.5 \mathrm{~cm}, P=0.079)$ (Fig. $4 \mathrm{~b})$ or percentage change in hand dominance $(10.1 \pm 2.1 \%$ vs. $15.8 \pm 3.3 \%$, $P=0.169$ ) (Fig. 4d).

Object positioning

In this subcategory, there was a significant improvement between the assessment before and after training in terms of:

- $\quad$ task time $(280.1 \pm 40.3$ s vs. $106.6 \pm 5.1$ s, $P=0.028)$ (Fig. 5a),

- $\quad$ ath length $(825.3 \pm 48.3 \mathrm{~cm}$ vs. $463.4 \pm 16.8 \mathrm{~cm}, P<$ 0.001 ) (Fig. 5b) and
Fig. 5 Change in object positioning skills following box trainer use. $C H P$ change in hand preference, $E O M$ economy of movement. $* P<0.05, \# P<0.001$, ANOVA
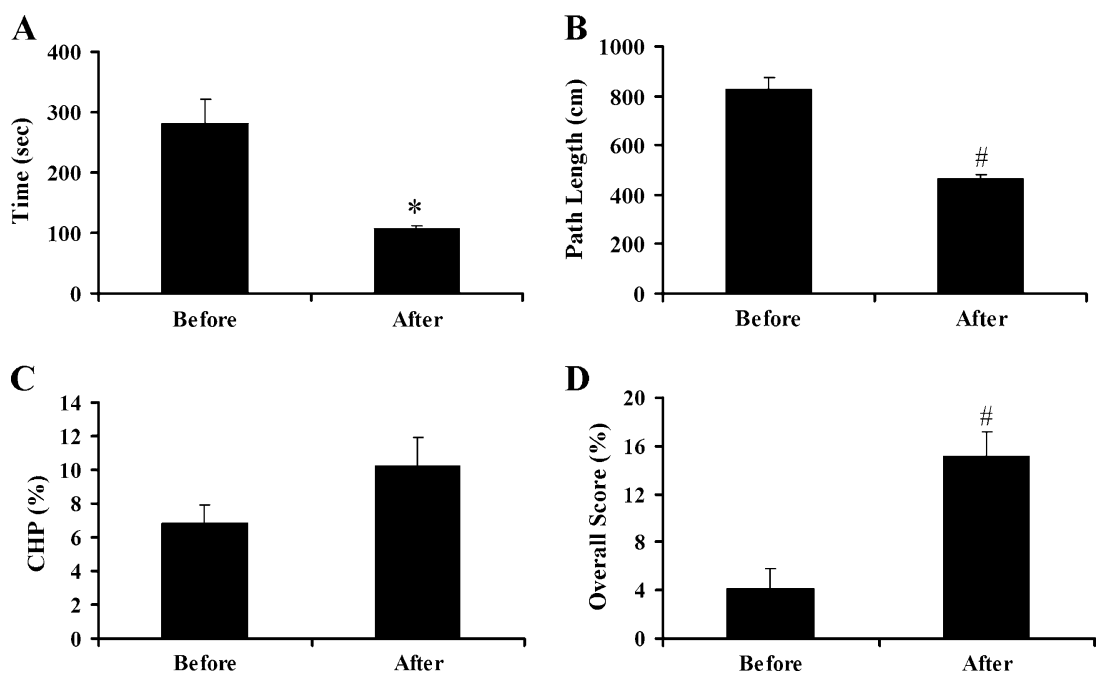
- overall score $(4.2 \pm 1.7 \%$ vs. $15.2 \pm 2.0 \%, P<0.001)$ (Fig. 5d).

There was however no difference between the assessment before and after training in terms of percentage change in hand dominance $(6.8 \pm 1.1 \%$ vs. $10.2 \pm 1.7 \%, P=0.127)$ (Fig. 5c).

\section{Discussion}

Globally, increasing number of gynaecological surgeries is being performed laparoscopically. Because of the European Working Time Directive, there is decreasing time to train surgeons. It is now more important than ever to improve the surgical skills in the least time with maximum efficiency [18].

Virtual reality has been proven to improve surgical skills $[14,16,19]$. However, virtual reality training is expensive and is not readily available to most trainees. In that respect, training using a 'take home' box trainer becomes more attractive. Our study has clearly supported the fact that skills acquired using a 'take home' box trainer would improve laparoscopic skills as measured by performance on a virtual reality laparoscopic simulator.

In this study, significant improvement was demonstrated in tissue manipulation and object positioning exercises. This was expressed by a reduction in total task time and an increase in overall score for both exercises as well as an improvement in economy of movement in tissue manipulation exercise and a decrease in path length in object positioning.

In the tissue manipulation exercise, there was no change in path length. This may be explained by the fact that, in this exercise, simulated tissue is stretched from one fixed point to another as directed by the computer. Hence, the overall path length would remain the same. However, a better measurement of skill in this exercise was economy of movement, which analysed how effective the tissues were moved from one point to another with the least tissue manipulation and instrument handling.

In the object positioning exercise, besides reduction in task time and overall score, there was also a reduction in path length. A reduction in path length may suggest that there was a more fluent and successful first time transfer of objects between one hand and the other and less accidental drop of the objects. This is further supported by the fact that task time was also reduced. These demonstrate an overall improvement on laparoscopic dexterity.

In regards to locating and coordinating exercise, there was no statistically significant difference in task time, path length, hand dominance or overall score. This can be explained by the fact that the participants were not laparoscopic 'novices' and because this exercise is basic, such that the performance at the start of the course was good with small room for improvement in this particular group. As regards to percentage change in hand dominance, the lack of improvement in all three exercises may indicate that a 6-month training period may not be sufficient enough time to cause significant change in the nondominant hand. It may also show a need to develop exercises on the box trainer to increase dexterity in the non-dominant hand.

Studies have reported that an improvement on performance on a virtual reality laparoscopic simulator as indicated by improved score on different exercises translates into improved operative performance $[20,21]$. Our study has shown that practice on a 'take home' box trainer also improved performance on the laparoscopic simulator and should logically be reflected in improved laparoscopic skill in vivo. Moreover, assessing performance on the virtual laparoscopic simulator at regular intervals after practising on a box trainer may be a more reliable way of assessing improvement in surgical skills as improved score on the simulator after repeating the exercises on the simulator itself may be due to increased familiarity with the exercises rather than improved surgical skills.

Those two hypotheses can be explored by having a group of registrars train on the virtual reality simulator and another on the box trainer. Their progress can then be assessed during laparoscopic surgery by independent viewers (consultants and nurses) blinded as to which group they belong. This will directly measure if training on box trainers improves laparoscopic skill in vivo and whether the degree of improvement on the virtual simulator is comparable to the improvement noted during laparoscopic surgery.

In retrospect, our study was limited by the fact that we did not have a control group. However, we did not identify any other factors such as increase in number of laparoscopic procedures performed per week by each participant, during the 6month period that would have contributed to an improved score on the virtual reality machine other than the course itself and training on the box trainer.

\section{Conclusion}

In conclusion, we have shown that a 'take home' box trainer improves laparoscopic performance on many exercises as scored by the virtual reality simulator and could therefore be a more accessible, realistic and cost-effective tool for those training to become laparoscopic surgeons.

Acknowledgements We would like to thank all the participants of the course and study.

Declaration of interest Walter Prendiville and Ray O'Sullivan are directors of Endosim Ltd and possess patents related to Laprotrain. Kushal Chummun and John Burke have no conflicts of interest or financial ties to disclose. 


\section{References}

1. Jones DB, Brewer JD, Soper NJ (1996) The influence of threedimensional video systems on laparoscopic task performance. Surg Laparosc Endosc 6:191-197

2. Wolfe BM, Szabo Z, Moran ME, Chan P, Hunter JG (1993) Training for minimally invasive surgery: need for surgical skills. Surg Endosc 7:93-95

3. Melvin WS, Johnson JA, Ellison EC (1996) Laparoscopic skills enhancement. Am J Surg 172:377-379

4. Dent TL (1992) Training, credentialing, and evaluation in laparoscopic surgery. Surg Clin North Am 72:1003-1010

5. Munz Y, Kumar BD, Moorthy K, Bann S, Darzi A (2004) Laparoscopic virtual reality and box trainers: is one superior to the other? Surg Endosc 18(3):485-494

6. Farnworth LR, Lemay DE, Wooldridge T, Mabrey JD, Blaschak MJ, DeCoster TA, Wascher DC, Schenck RC Jr (2001) A comparison of operative times in arthroscopic ACL reconstruction between orthopaedic faculty and residents: the financial impact of orthopaedic surgical training in the operating room. Iowa Orthopedic Journal 21:31-35

7. Babineau TJ, Becker J, Gibbons G, Sentovich S, Hess D, Robertson S, Stone M (2004) The "cost" of operative training for surgical residents. Archives of Surgical Research 139(4):366-370

8. Wilkiemeyer M, Pappas TN, Giobbie-Hurder A, Itani KM, Jonasson O, Neumayer LA (2005) Does resident postgraduate year influence the outcomes of inguinal hernia repair? Ann Surg 241(6):879-884

9. Kauvar DS, Braswell A, Brown BD, Harnisch M (2006) Influence of resident and attending surgeon seniority on operative performance in laparoscopic cholecystectomy. J Surg Res 132(2):159-163

10. Anastakis DJ, Regehr G, Reznick RK, Cusimano M, Murnaghan J, Brown M, Hutchison C (1999) Assessment of technical skills transfer from the bench training model to the human model. Am J Surg 177:167-170

11. Hunter JG, Sackier JM, Berci G (1994) Training in laparoscopic cholecystectomy: quantifying the learning curve. Surg Endosc 8:28-31
12. Rowan AN (1993) Is justification of animal research necessary? JAMA 269:1114

13. Hyltander A, Liljegren E, Rhodin PH, Lonroth H (2002) The transfer of basic skills learned in laparoscopic simulator to the operating room. Surg Endosc 16(9):13248

14. Seymour NE, Gallagher AG, Roman SA, O'Brien MK, Bansal VK, Andersen DK, Satava RM (2002) Virtual reality training improves operating room performance: results of a randomized, double-blinded study. Ann Surg 236(4):458-464

15. Watterson JD, Beiko DT, Kuan JK, Denstedt JD (2002) Randomized prospective blinded study validating acquistion of ureteroscopy skills using computer based virtual reality endourological simulator. J Urol 168(5): 1928-1932

16. Grantcharov TP, Kristiansen VB, Bendix J, Bardram L, Rosenberg J, Funch-Jensen P (2004) Randomized clinical trial of virtual reality simulation for laparoscopic skills training. Br J Surg 91 (2):146-150

17. Moorthy K, Munz Y, Jiwanji M, Bann S, Chang A, Darzi A (2004) Validity and reliability of a virtual reality upper gastrointestinal simulator and cross validation using structured assessment of individual performance with video playback. Surg Endosc 18 (2):328-333

18. Chikwe J, de Souza AC, Pepper JR (2004) No time to train the surgeons. BMJ 328(7437):418-419

19. Aggarwal R, Tully A, Grantcharov T, Larsen CR, Miskry T, Farthing A, Darzi A (2006) Virtual reality simulation training can improve technical skills during laparoscopic salpingectomy for ectopic pregnancy. BJOG 113(12):1382-1387

20. Scott DJ, Bergen PC, Rege RV, Laycock R, Tesfay ST, Valentine RJ, Euhus DM, Jeyarajah DR, Thompson WM, Jones DB (2000) Laparoscopic training on bench models: better and more cost effective than operating room experience? J Am Coll Surg 191 (3):272-283

21. Kirby TO, Numnum TM, Kilgore LC, Straughn JM (2008) A prospective evaluation of a simulator- based laparoscopic training program for gynecology residents. J Am Coll Surg 206(2):343348 